\title{
LA LICENCIA URBANÍSTICA DE OBRAS COMO INDICADOR DE LOS PROCESOS DE RENOVACIÓN DE LOS DESTINOS TURISTICOS MADUROS DE LITORAL'
}

\author{
Moisés Simancas Cruz \\ Agustín Dorta Rodríguez \\ Héctor Dávila Mamely \\ Grupo de investigación ReinvenTUR: Renovación e Innovación Turística. Universidad de La Laguna. \\ Observatorio de Renovación Turística. Cátedra de Turismo CajaCanarias-Ashotel-Universidad de La Laguna \\ msimancas@ull.edu.es, agustin.drguez@gmail.com, hmamely@gmail.com
}

\section{RESUMEN}

La renovación de la oferta de alojamiento turístico constituye uno de los ejes claves de las múltiples estrategias de reestructuración de los destinos turísticos en fase de declive, e incluso, decadencia. Su medición implica la utilización de indicadores mensurables. Uno de ello es el número de licencias urbanísticas de obra otorgadas para acometer operaciones de renovación edificatoria (física) en tales establecimientos. Este trabajo plantea las potencialidades y debilidades de su uso, así como la metodología para el análisis de procesos de regeneración de áreas turísticas maduras. Para ello se utiliza como ejemplo lo sucedido en Puerto de la Cruz entre 1950 y 2009, uno de los destinos turístico primigenios de las Islas Canarias (España).

Palabras clave: alojamientos turísticos, renovación, licencias de obras, Puerto de la Cruz, destinos maduros.

Fecha de recepción: julio 2015.

Fecha de aceptación: marzo 2016.

1 La investigación que da lugar a esta publicación se inscribe en el proyecto titulado "Crisis y reestructuración de los espacios turísticos del litoral español" (CSO2015-64468-P) del Ministerio de Economía y Competitividad (MINECO). Asimismo, constituye uno de los resultados del proyecto "SIGturCanarias: Tecnologías de Información Geográfica aplicadas al análisis y diseño de propuestas innovadoras para la renovación de los alojamientos turísticos", financiado por la Fundación CajaCanarias y gestionado por el Vicerrectorado de Investigación de la Universidad de La Laguna. 


\section{ABSTRACT}

The renewal of the supply of tourist accommodation is one of the key axes of the multiple strategies of restructuring of tourist destinations in decline phase, and even decline. Measurement involves the use of measurable indicators. One of this is the number of work planning permission granted to undertake renovation operations (physical) in such establishments. This paper focuses on the strengths and weaknesses of their use, and the methodology for the analysis of processes of regeneration of mature tourist areas. For it is used as an example what happened in Puerto de la Cruz between 1950 and 2009, one of the primordial tourist destinations in the Canary Islands (Spain)

Keywords: tourist accommodation, renovation, building permits, Puerto de la Cruz, mature destinations.

\section{INTRODUCCIÓN}

La obsolescencia (física, funcional, de modelo de negocio, de modelo organizativo, formas de segmentación, canales de venta, etc.) de un establecimiento de alojamiento turístico no surge necesariamente por un mal funcionamiento de su gestión, sino porque su morfología, utilidad o funcionalidad se vuelve insuficiente o es superada por los gustos, motivaciones y exigencias de la demanda (Williams y Montanari, 1995; Antón, 2004), y, por ende, a las nuevas tendencias del mercado, a la que no puede adaptarse y dar una respuesta. Por tanto, se trata de una situación de old-fashioned (pasado o fuera de moda), que puede corregirse a través de actuaciones de renovación.

Sin embargo, la ausencia de tales operaciones de renovación resulta habitual ante una situación de deterioro continuo de los márgenes empresariales y una cierta descapitalización. Las inversiones en las mismas suelen ser dependientes de los márgenes de beneficios, de modo que sólo se abordan bajo condiciones en las que puedan recuperarse vía precio de contratación (González, León y Padrón, 2006); además, los propietarios de los inmuebles o los empresarios responsables de su gestión están más pendientes de afrontar obras de conservación y mantenimiento, así como de adaptación a la normativa en materia de instalaciones y seguridad (Yepes, 1996). Ello ha acentuado su deterioro y desfase, siendo susceptible de acentuarse a medio y largo plazo, al disminuir tanto la rentabilidad como la diversidad y la calidad de los servicios. Este proceso ha provocado una pérdida de su capacidad de atracción, competitividad, cuota de mercado y rentabilidad empresarial, con el consiguiente impacto sobre los principales indicadores del negocio turístico y de la rentabilidad empresarial (número de pernoctaciones, estancia media, índices de ocupación, tarifa media diaria, ingreso medio diario por habitación disponible y ocupada, etc.).

Ésta suele contrarrestarse con la aplicación de una política agresiva de descuentos, que ha generado un círculo vicioso de precios ajustados, con la consiguiente modificación de los segmentos y patrones de demanda hacia menor calidad-diferenciación (Knowles y Curtis, 1999), así como la producción de bienes y servicios homogéneos, de baja calidad y fácilmente sustituibles. Si bien ello posibilita unos niveles mínimos de ocupación 
que garantizan una rentabilidad que, al menos, cubren los costes de explotación y, en el mejor de los casos, de mantenimiento y ornato, no sucede lo mismo con los márgenes de beneficios, que siguen reduciéndose, con la consiguiente repercusión sobre la disponibilidad de fondos económicos susceptibles de ser destinados a la modernización, mejora y cualificación parcial y/o total de las instalaciones, equipos y servicios turísticos. Todo ello repercute en una reducción de la rentabilidad privada y social del negocio turístico (depreciación), que, a su vez, explica la elevada rotación de la propiedad, cuando no se cumplen las expectativas de amortización y generación de beneficios, así como el citado cambio de uso de los inmuebles, pasando del turístico al residencial. Estas estrategias competitivas han conllevado, a menudo, importantes efectos "descualificadores" (Santos y Fernández, 2010), que han profundizado en la espiral desvalorizadora del litoral turístico (Prats, 2003; López Olivares et al., 2005).

Sin embargo, considerando que los establecimientos de alojamiento turístico constituyen verdaderos "activos" de los destinos turísticos y como parte de este potencial turístico, su renovación resulta esencial. Esta incluye tanto actuaciones físicas sobre el hardware, como intervenciones sobre elementos más relacionados con la operativa y la funcionalidad, es decir, el software (Simancas y Hernández, 2015). En general, las actuaciones de renovación exitosas incluyen acciones que trascienden a la intervención física y, por supuesto, a la mera rehabilitación edificatoria. Así, los procesos de renovación deben afrontar cambios e innovaciones en los distintos elementos del sistema de alojamiento turístico, como el modelo de negocio, la comercialización, la forma de gestión empresarial, la estructura organizativa y de los recursos humanos, la prestación de servicios, etc. En nuestro caso, consideramos que el diseño de los modelos de negocio para cada alojamiento debe determinar, entre otros aspectos, las reformas físicas a acometer en el mismo.

La renovación de alojamientos turísticos se plantea en torno a actuaciones de innovación y de creación de nuevos productos que sean atractivos, diferenciados y que estén dirigidos a diversos segmentos de clientes. Sus ventajas son múltiples. En primer lugar, permiten el incremento de los niveles de excelencia y calidad turística de la oferta de alojamiento turístico, incidiendo en su cualificación, la incorporación de nuevos productos alojativos (experiencias, servicios y comodidades), que permite captar nuevos clientes, su adecuación a las necesidades del mercado, las exigencias de la demanda, la implementación de nuevos modelos de negocio, etc. En segundo lugar, rompe la tradicional estrategia de rejuvenecimiento de la oferta de alojamiento turístico básicamente a través de la introducción de nuevas plazas turísticas, intensificando el mencionado proceso de depreciación y cambio de uso de las obsoletas; ello ha producido una situación paradójica: mientras que las urbanizaciones turísticas más recientes han "colonizado" nuevos espacios, las más antiguas, con peores condiciones de explotación y competitividad, se han localizado en los sectores de litoral más privilegiados desde el punto de vista del potencial turístico. En tercer lugar, genera empleo, posibilitando, sobre todo, la contratación de mano de obra parada procedente del sector de la construcción. En cuarto lugar, incide positivamente en los citados indicadores del negocio turístico y de la rentabilidad empresarial de los alojamientos. Del mismo modo, previene o corrige el deterioro o la "mala" imagen de las edificaciones turísticas que puede representan una pérdida de calidad turística al destino (incluyendo procesos de demolición y esponjamiento o reconversión). Asimismo, permite 
integrar innovaciones, soluciones técnicas actualizadas y obligaciones normativas relacionadas con el uso eficiente de energías y consumos de agua, así como la incorporación de soluciones arquitectónicas bioclimáticas en los equipamientos, cuestiones cada vez más apreciadas por los clientes. Por último, posibilitan el incremento de categoría, e incluso, el cambio de modalidad de alojamiento turístico.

Por consiguiente, la renovación de los alojamientos turísticos se revela como una estrategia clave de cualquier política de reposicionamiento competitivo de las áreas turísticas maduras. Esto ha sido puesto de manifiesto, entre otros, por Yepes (1996), Donaire y Mundet (2001), Agarwal (2002), Antón (2004 y 2011), Potter y Phillips (2004), Clegg y Essex (2000), Santos y Fernández (2010), López y Ferreres (2011), Fuster et al. (2010), Obiol y Ferrandis (2012), Vera y Baños (2010), Vera, Rodríguez y Capdepón (2010), Antón (2011), Duro (2012), González Reverté (2012), e Ivars, Rodríguez y Vera (2013).

La renovación de los establecimientos de alojamiento turístico se ha planteado como un elemento estructural de la política turística de las Islas Canarias (España), siendo analizada por Mirallave (2004), González et al. (2006), Chinchilla (2009), Dorta (2010, 2011, 2013, 2015 y 2016), Dorta y García (2010), Llorca y Sosa (2010), García (2010 y 2015), Simancas (2010, 2011, 2013 y 2015), Simancas y García (2010) y Villar (2016). Esta se inició con el Decreto 4/2001, de 12 de enero, por el que se acordó la formulación de las Directrices de Ordenación General y las del Turismo (DOT), que continuó con la Ley 19/2003, prolongándose hasta la actualidad con la promulgación de la Ley 9/2015, de modificación de la Ley 2/2013, de 29 de mayo, de Renovación y Modernización Turística de Canarias. Esta estrategia pretende la reconversión de aquellas calificables como "agotadas" en función de un nivel de densidad excesivo y deficiencias de servicios, así como el establecimiento de las bases para el cambio de modelo del producto turístico (sustitución de establecimientos alojativos dispersos por complejos de mayor nivel de servicios), siendo de especial aplicación a medio y largo plazo, sobre todo, en dos tipos de áreas turísticas: a) aquellas "cuya oferta turística se encuentra en declive o en riesgo de entrar en declive" al producirse su inadecuación, debido a la antigüedad de los edificios y a la necesidad de su adaptación a los requerimientos de la demanda (DOT 20.4.b), como reflejan los bajos índices de satisfacción, los problemas de comercialización y el descenso de la ocupación respecto de otros ámbitos de la misma zona turística (DOT 20.4.d); y b) aquellas áreas "saturadas", en cuanto su capacidad de carga se encuentra agotada (DOT 25.2.e y 26.4), en los que, además de impedir la construcción de nuevos crecimientos turísticos, es precisa la disminución de su densidad y capacidad alojativa (DOT 20.3.a), sobre todo, en los casos en los que se supera el límite de densidad bruta de 200 plazas por hectárea (DOT 20.4.c), así como es precisa la corrección de los déficit en infraestructuras y equipamientos. Por su parte, en el artículo 2 del Decreto 138/2010, de 23 de septiembre, por el que se desarrolla la previsión en materia de rehabilitación de establecimientos turísticos contenida en la Ley 6/2009 (BOC n 197, de 5 de octubre) define la situación de deterioro y de obsolescencia de un establecimiento de alojamiento turístico: mientras que para la primera se produce cuando se da una falta de conservación, un menoscabo y un quebranto que presentan los elementos estructurales y accesorios del edificio, las instalaciones o dotaciones técnicas y el equipamiento turístico complementario, de ocio, salud o deportivas del mismo, la de obsolescencia se refiere a aquella que se produce por un grado 
de inadecuación de la funcionalidad, la seguridad, la habitabilidad o calidad ambiental del edificio, del equipamiento turístico complementario de ocio, salud, deportivas o de esparcimiento o de las instalaciones técnicas, a la ordenación turística vigente o, en general, a la normativa que fuera de aplicación.

Desde este punto de vista, cualquier obra mayor o menor que se vaya a realizar precisa de la correspondiente licencia urbanística de obras ("el permiso de construcción"). Ello las convierte en uno de los múltiples indicadores que permiten describir el proceso de renovación física (edificatoria) de los establecimientos turísticos. Ello se debe a que, entre otras cuestiones, constituyen el mecanismo del que dispone la Administración competente para fiscalizar determinados actos con carácter previo a su realización. Así, su análisis no sólo permite identificar cuantitativamente el número, tipología y características de las reformas acometidas, sino también sirve para indicar cuestiones no percibidas, como la existencia de un ritmo de otorgamiento, la percepción empresarial, etc.

El principal objetivo de este trabajo es aportar las fortalezas y debilidades del uso de las licencias urbanísticas otorgadas para medir los procesos de renovación de destinos turísticos maduros. Con el fin de dotar de una dimensión aplicada — no especulativa- a los diferentes enunciados generales, nos basamos en el proceso de renovación de los alojamientos turísticos de Puerto de la Cruz (Tenerife, España).

\section{LA RELEVANCIA DE LA LICENCIA URBANÍSTICA DE OBRAS COMO INDICADOR DEL GRADO DE RENOVACIÓN DE LOS ESTABLECIMIENTOS DE ALOJAMIENTO TURÍSTICO}

La licencia urbanística de obra es un acto administrativo de carácter declarativo —no constitutivo-, obligatorio, objetivo, neutral y motivado de otorgamiento o denegación de un permiso o autorización del ius aedificandi. Por tanto, se trata de un acto de autorización (de la Concha, 2010). Así, como señalan García de Enterría y Parejo Alfonso (1981), "la licencia urbanística constituye uno de los supuestos más genuinos de aplicación de la técnica autorizatoria entendida como remoción o alzamiento de una prohibición legal de ejercicio de un derecho su objetivo perfecto impuesta por la necesidad de contrastar previamente que dicho ejercicio se atiene a los límites que configuran el propio derecho según la ordenación urbanística".

En relación con la renovación de los establecimientos de alojamiento turístico, en virtud del artículo 166 del Decreto Legislativo 1/2000, de 8 de mayo, por el que se aprueba el Texto Refundido de las Leyes de Ordenación del Territorio de Canarias y de Espacios Naturales de Canarias (TRLOTENC en lo sucesivo), todas las obras de demolición o ampliación de construcciones, edificaciones e instalaciones, de modificación o reforma que afecten a su estructura o a aspecto exterior, o las que modifiquen la disposición interior de las mismas, están sujetos a previa licencia urbanística municipal, sin perjuicio de las demás autorizaciones o informes que sean procedentes de acuerdo con la legislación sectorial aplicable.

Desde este punto de vista, la relevancia del análisis del proceso de otorgamiento de licencias para actuaciones destinadas a la renovación de los alojamientos turísticos radica en que aporta una interesante información cuantitativa acerca de la misma.

En primer lugar, se trata de un procedimiento reglado — no discrecional—, ciñendo su actuación estrictamente a la comprobación de la conformidad de la actividad proyectada 
por el solicitante a la citada legalidad, siendo irrelevantes sus circunstancias y condiciones subjetivas o personales. Así, tiene naturaleza declarativa, en cuanto no crea ni constituye un derecho nuevo, sino que simplemente lo reconoce. Tampoco otorga el derecho a realizar el acto, cuya legitimidad controla, pues éste ya ha sido atribuido por la ordenación urbanística; se circunscribe a verificar si el ejercicio de tal derecho está dentro de los límites del planeamiento y se produce con el cumplimiento de los deberes exigibles. En cualquier caso, en virtud del artículo 7.2.b) del TRLOTENC supone una forma de gestión para las actuaciones que impliquen ejercicio de las potestades de ordenación, inspección, control, intervención, protección de la legalidad, sanción y expropiación. Asimismo, excluye el libre ejercicio del ius aedificandi y controla que la actuación que se pretende realizar esté de acuerdo con la ordenación urbanística aplicable. Del mismo modo, la licencia otorga a la Administración un título ejecutorio para la imposición de sanciones por infracciones derivadas de su incumplimiento (artículo 202 TRLOTENC) o de su ausencia.

En segundo lugar, la licencia se otorga propter rem y no intuitu personae (de la Concha, 2010). Ello determina la no exigibilidad de la condición de propietario para obtenerla (artículo 12.1 del Reglamento de Servicios de las Corporaciones Locales) y su esencial transmisibilidad (artículo 13.1 del mismo Reglamento). Ello posibilita que la licencia pueda ser solicitada por propietarios y las cadenas hoteleras o holdings que gestionan los establecimientos de alojamiento turístico a través de fórmulas de franquicia, contratos de arrendamiento, de explotación o similares.

En tercer lugar, constituye un acto de policía o de intervención en la esfera de las libertades individuales. Su obtención legitima la materialización de los actos de ejecución de cualquier tipo de actuación o construcción y el desarrollo de los usos y actividades correspondientes. Supone el mecanismo del que dispone la Administración competente para fiscalizar determinados actos con carácter previo a su realización, cumpliendo los requisitos exigidos por el órgano local durante la construcción o para recibir el certificado de ocupación del alojamiento turístico (Corgel, Deroos and Fitzpatrick, 2011). A diferencia de la licencia de apertura, que pretende constatar si las instalaciones reúnen las condiciones exigidas por la normativa sectorial (ruidos, accesibilidad, protección contra incendios, medio ambiente, etc.), a fin de evitar que el funcionamiento de una actividad determinada produzca molestias o daños, la de obras supone un instrumento de verificación de la conformidad y concordancia del acto proyectado y solicitado por el promotor con el interés general representado por la legislación de aplicación y los instrumentos de planificación territorial y de planeamiento urbanístico. De esta manera, la licencia sólo está sometida a conditiones iuris y no a conditiones facti (De la Concha, 2010). Por tanto, constituye la garantía de una mejor cobertura jurídica del interés general, en cuanto desplaza la prohibición de ejercicio de derechos subjetivos (ius aedificandi y de uso del suelo y subsuelo), que impone el ordenamiento jurídico, por la necesidad de constatar anticipadamente que dicho ejercicio no vulnera los intereses generales que tutela la Administración competente.

Por tanto, en coherencia con la Sentencia del Tribunal Supremo de 5 de febrero de 1996, se trata de una autorización previa a la realización de las correspondientes obras, cuyo contenido se agota en la comprobación de la adecuación del concreto ejercicio de la facultad dominical a la citada legalidad, lo cual lo convierte en un mecanismo de control preventivo. Ello pone de manifiesto que, en muchas ocasiones, suponen un factor de retraso en las ope- 
raciones de renovación del establecimiento de alojamiento turístico ante las dificultades de obtener los permisos necesarios para su ejecución (Abdelghany and Abotaleb, 2014). En otras, por lo contrario, la obtención de licencia y autorización para la renovación de los alojamientos se simplifica (Artiguez y Blázquez, 2012), llegando al extremo de ser suficiente una «declaración responsable» del interesado para el inicio de la actividad como ocurriera con el Decreto Ley 1/2009, de 30 de enero, de medidas urgentes para el impulso de la inversión en las Islas Baleares (BOIB, nº 17 ext., 2/2/2009).

En cuarto lugar, su otorgamiento es una competencia exclusiva de la Administración municipal. Esto permite que los expedientes puedan consultarse en las oficinas técnicas o similares de los ayuntamientos. No obstante, en el caso de Canarias, los acuerdos de concesión de licencias que contengan autorización relativa a establecimientos de alojamiento turístico deben ser notificados al Cabildo Insular correspondiente, en el plazo de quince días siguientes a la fecha del acuerdo (artículo 166.7 del TRLOTENC).

Por último, el análisis de las licencias de obras concedidas aporta una importante cantidad de información acerca de los procesos de renovación de los establecimientos de alojamiento turístico, sobre todo, relativa a su utilización estadística. Esta da cuenta de la cantidad de actuaciones de renovación acometidas, su objeto material, entendido como la zona de la realidad física alterada sobre la que se proyecta, y, por tanto, el tipo de actuación, así como el presupuesto económico. Para ello resulta interesante analizar los dos tipos de licencias, de obra mayor y menor.

El punto 3.5 del Anexo del TRLOTENC define la obra mayor como aquella de construcción y edificación de técnica compleja y cierta entidad constructiva y económica, cuyo objeto material suponga una alteración de volumen, del uso objetivo de las instalaciones y servicios de uso común o del número de viviendas y locales, o del número de plazas alojativas turísticas o afecte al diseño exterior, a la cimentación, a la estructura o las condiciones de habitabilidad o seguridad de las construcciones, los edificios y las instalaciones de todas clases. En relación con la renovación edificatoria de los alojamientos turísticos, se trata de acometer actuaciones de renovación que, aprovechando los elementos estructurales y accesorios del edificio, impliquen, como mínimo, la modernización estética (ornato) y, sobre todo, la actualización y mejora de las unidades alojativas y de los espacios comunes, de modo que, si bien se mantienen las características tipológicas y funcionales básicas del inmueble, se aborda una modificación en profundidad de los elementos menos duraderos (instalaciones, pavimentos, acabados, carpinterías interiores y exteriores, sanitarios y otros) (Simancas, 2010).

Por tanto, las obras mayores se van a corresponder con las denominadas "rehabilitaciones integrales" de la Ley 6/2009, de 6 de mayo, de medidas urgentes en materia de ordenación territorial para la dinamización sectorial y la ordenación del turismo, y "totales" de la 2/2013, de 29 de mayo, de Renovación y Modernización Turística de Canarias, que deroga a la norma anterior. Para ello, los establecimientos turísticos de alojamiento deben encontrarse en la situación denominada en Ley 6/2009 como "de deterioro" u "obsolescencia": mientras que la primera calificación implicó una falta de conservación, menoscabo y quebranto de los elementos estructurales y accesorios tanto del edificio, como de las instalaciones o dotaciones técnicas y el equipamiento turístico complementario, de ocio, salud o deportivas del mismo, la segunda supone un grado de inadecuación a la ordenación 
turística vigente o, en general, a la normativa que fuera de aplicación, en lo relativo a la funcionalidad, seguridad, habitabilidad o calidad ambiental del propio edificio, del equipamiento turístico complementario de ocio, salud, deportivas o de esparcimiento o de las instalaciones técnicas.

Por su parte, la jurisprudencia tiene declarada que el significado de obra menor es un concepto jurídico indeterminado (Sentencia del Tribunal Supremo de 20 de junio de 1988), que se ha de precisar caso por caso (vía casuística) y en consideración al volumen de las obras, a la transcendencia o peligro para la efectividad de la ordenación urbanística, y a la complejidad o sencillez del proyecto. De esta manera, al no existir una definición de obras menores en el TRLOTENC y en legislación estatal relativa a esta materia, como tales se entiende, de acuerdo con sentada doctrina jurisprudencial, a todas aquellas obras que no afecten a la estructura o elementos sustentantes de un inmueble y que, además, sean de sencillez técnica y de escasa entidad constructiva y económica, como son las de simple reparación, decoración o cerramiento y que además no precisan de presupuesto elevado. Desde el punto de vista técnico, comprende aquellas actuaciones vinculadas a la rehabilitación edificatoria, y, por tanto, las operaciones de estricto mantenimiento y ornato (conservación) (Simancas, 2010), siempre que no supongan la alteración del volumen, la afección al diseño exterior, la estructura o la cimentación de las instalaciones turísticas (Dorta, 2015). Por consiguiente, se trata de obras sencillas, no siendo necesaria la redacción completa de un proyecto técnico, por lo que existe una mayor agilidad en cuanto a la tramitación de la documentación oportuna.

En definitiva, la licencia urbanística de obra constituye una de las modalidades de intervención administrativa sobre la actividad privada, a modo de control previo a su puesta en marcha. Así, supone un impeditivo de la misma de no concurrir todos los requisitos legalmente exigidos, una resolución formal declarativa de un derecho — a realizar la actividad, a la vez que condiciona el plazo de inicio de la edificación y, por ende, su eficacia; en este sentido, recuérdese que la licencia no otorga un derecho a edificar sino a ejercitarlo, al tratarse de un derecho preexistente a la solicitud, que se integra en el patrimonio jurídico del solicitante por el cumplimiento de los deberes de cesión, equidistribución y urbanización inherentes al proceso de transformación del suelo.

\section{PLANTEAMIENTO DEL PROBLEMA. LA INFORMACIÓN DISPONIBLE PARA MEDIR LA RENOVACIÓN DE LOS ALOJAMIENTOS TURÍSTICOS: EL USO DE LA LICENCIA URBANÍS- TICA DE OBRA MAYOR Y MENOR}

Estas fortalezas de las licencias urbanísticas son contrarrestadas por un conjunto de debilidades, que limitan su alcance en el análisis de los procesos de renovación de alojamiento turístico.

En primer lugar, la licencia no actúa como una unidad de análisis homogénea. Ello se debe, en gran medida, a la heterogeneidad de la normativa y legislación autonómica y municipal. El principal efecto es la ausencia de criterios homogéneos para la medición de variables en torno a los tipos de licencia.

En segundo lugar, determinadas actuaciones de renovación física de los establecimientos de alojamiento se han ejecutado sin la correspondiente licencia urbanística, para evitar los 
costes asociadas (tasa por prestación de servicios urbanísticos, tasa por la utilización privativa del dominio público local, impuesto de construcciones instalaciones y obras, dirección facultativa, etc.).

En tercer lugar, el cuestionario del Ministerio de Fomento de la Dirección General de programación económica y Subdirección General de estadísticas y estudios del Gobierno de España recoge información a escala nacional sobre licencias de obra mayor, como parte de la Estadística de construcción de edificios del estado español. Este cuestionario recopila, con una periodicidad anual y mensual, información de forma anticipada de todo el ámbito territorial nacional, tanto de forma autónoma como a través de acuerdos de colaboración con algunas Comunidades Autónomas (Principado de Asturias, Canarias, Castilla y León, Cataluña, Galicia, Región de Murcia, Comunidad Foral de Navarra y País Vasco), donde los servicios de la administración autonómica son los encargados de recibir, recoger y tratar la información de sus municipios; por tanto, las unidades de información las constituirán las licencias de obra mayor en edificación concedidas por los ayuntamientos. Este formulario debe rellenarse y entregarse en el correspondiente ayuntamiento por parte del promotor o responsable del proyecto en el momento de solicitar la licencia urbanística de obra mayor; de esta manera, la unidad informante es el colectivo de promotores inmobiliarios y/o técnicos colegiados que firman los proyectos de edificación. Contiene diversos módulos de preguntas, en los que se contemplan los grandes rasgos sobre la edificación de nueva planta, la rehabilitación y la demolición (total o parcial) de edificios. Asimismo, contiene un apartado específico sobre obras de rehabilitación, que agrupa a las intervenciones de ampliación, reforma y/o restauración; así, aporta información relevante sobre la tipología y características de la obra.

Sin embargo, este cuestionario presenta una serie de problemas estadísticos para el análisis de los procesos de renovación de los alojamientos turísticos:

- Las licencias correspondientes a los establecimientos turísticos no se diferencian del resto.

- La información resulta insuficiente y básica si lo que se intenta es profundizar en los procesos de renovación de la oferta de alojamiento turístico.

- El cuestionario presta especial atención a la construcción de edificaciones de nueva planta y no desglosa la información de manera exhaustiva para estudios analíticos en profundidad. Si bien resulta interesante desde la perspectiva de conocer los procesos de crecimiento, expansión y esponjamiento urbano y de rejuvenecimiento urbano vía construcción, el cuestionario no permite un mayor aprovechamiento de los datos estadísticos disponibles.

- Existe cierta ambigüedad para asignar la licencia a establecimientos de alojamientos ubicados en áreas turísticas de litoral. Ello se debe a que, dentro de las licencias de obra mayor para la construcción de edificios de nueva planta, el Ministerio de Fomento desglosa diferentes tipos de edificios en función de su naturaleza. Así, por ejemplo, en la medida en que los hoteles quedan catalogados como los destinados a residencia colectiva eventual como "edificios que el destino de los mismos es ser habitados por personas que ocupan espacios con sólo una relativa autonomía, pues existen una serie de servicios comunes: comedor, biblioteca, bar, sala de ocio que se 
utilizan indistintamente por todos los residentes del edificio" donde las personas no residirían por periodos largos o indefinidos y donde la forma de pago sería por días, no se puede diferencias la modalidad (hotelera o extrahotelera) y tipología (hotel, apartamento, villa, etc.) de oferta alojativa; ello se complica si consideramos que la legislación autonómica en esta materia es bastante heterogénea.

- Aunque se dispone de datos a escala nacional y autonómica sobre la cantidad de edificios rehabilitados, no se específica ningún aspecto más relacionado con la tipología hotelera o vinculado al sector turístico.

- Aunque se diferencian los campos de análisis disponibles para las obras de rehabilitación por edificación (total, ampliación, vaciado, cimentación, cubiertas, fachadas y número de locales reformados o acondicionados), identificando el mes/año, número y superficie, esta información resulta insuficiente para el análisis de la renovación de los alojamientos turísticos, en cuanto se limita a las obras de ampliación (en horizontal o en altura), el vaciado (conservando la fachada) o no del edificio, y la reforma o acondicionamiento de locales.

Aparte de los datos ofrecidos por el Ministerio de Fomento, resulta difícil acceder a información pública en este campo de análisis. La regulación sobre la concesión y utilización de la información procedente de las licencias de obras urbanísticas de obra mayor a escala regional y municipal queda supeditada a la competencia local y, por tanto, cada gobierno autonómico y, especialmente, los ayuntamientos resultan competentes para desarrollar su política de regulación de este derecho, atendiendo tanto a sus propias ordenanzas municipales, planes generales, planes especiales de rehabilitación, leyes sectoriales, etc., como a sus intereses económicos. Ello deriva en una amplia diversidad de casuísticas en torno a la figura de licencia de obra mayor, alcance, clasificación y tipologías de obras.

Este déficit de información se complica aún más, si cabe, para el caso de licencias de obra menor. Los diferentes ayuntamientos determinan diversos modelos para su solicitud. Así, los tipos de reforma y permisos son muy heterogéneos y varían en función de numerosos factores asociados a su localización. De igual modo, no se conoce cuestionario oficial por parte del Gobierno de España ni de otra institución a escala nacional para recabar información relativa a este tipo de licencias. Este problema también existe si aumentamos la escala de análisis, limitándose, en gran medida, a publicaciones puntuales de organismos o instituciones públicas, con información muy básica y normalmente imprecisa, a informes sobre la actividad de entidades relacionadas con el sector turístico (Patronatos de turismo, patronales hoteleras o similares), o a documentos de las propias cadenas o grupos hoteleros en los que se recoge los proyectos de renovación acometidos en sus establecimientos de alojamiento.

Teniendo en cuenta estos factores, se hace necesario otorgar el valor y reconocimiento preciso a la licencia urbanística que con sus fortalezas y debilidades supone un instrumento válido para el análisis de los procesos de renovación de los establecimientos de alojamiento turístico. Desde este punto de vista, a continuación, se expone la metodología usada en un destino turístico español de los años 50 para recabar información sobre la renovación edificatoria de la oferta de alojamiento a través de un uso exhaustivo de la licencia urbanística. 


\section{ESTUDIO DE CASO: LA MEDICIÓN DEL PROCESO DE RENOVACIÓN DE LA OFERTA DE ALOJAMIENTO TURÍSTICO DE PUERTO DE LA CRUZ A TRAVÉS DEL OTORGAMIENTO DE LICENCIAS URBANÍSTICAS DE OBRAS}

\section{IV.1. El tratamiento estadístico de las licencias de obras de renovación de Puerto de la Cruz}

Puerto de la Cruz es uno de los destinos turísticos de litoral primigenios de las Islas Canarias (España). A partir de la década de los años ochenta, éste comenzó a padecer claros síntomas de agotamiento, e incluso, declive (Alvarez, 2004; Martín Azami, 2005; Dorta y García, 2010; Dorta, 2011 y 2016; Ledesma, 2012). Ello se ha reflejado en los principales indicadores del negocio turístico (llegadas de turistas, número de pernoctaciones, estancia media, gasto, RevPar e índices de ocupación), puesto de manifiesto, entre otros, por Martín et al. (2011). La principal consecuencia es la aparición de procesos de obsolescencia en los espacios públicos y privados, en concreto, los establecimientos de alojamiento turístico. Algunos de éstos han alcanzado estados de depreciación, con la consiguiente salida del mercado de las plazas turísticas, al cerrase o transformarse en residenciales.

El análisis de las licencias de obra mayor y menor otorgadas en Puerto de la Cruz ha permitido la modelización del proceso de la renovación de los 90 establecimientos de alojamiento turístico existentes en esta área turística. Para ello se procedió a la recopilación de las resoluciones archivadas de licencia urbanística entre 1955 y 2009 en la Gerencia de Urbanismo y en el Archivo Municipal del Ayuntamiento de Puerto de la Cruz. Ello supuso identificar y cuantificar las operaciones legales de renovación, quedando fuera las realizadas sin licencia municipal. Esta operación no estuvo exenta de complicaciones:

- El Área de Urbanismo del Ayuntamiento de Puerto de la Cruz carecía de un registro específico en materia de turismo.

- No existía un sistema de clasificación interno para diferenciar las licencias correspondientes a las edificaciones turísticas (hoteles y apartamentos turísticos). Ello obligó la consulta de cada resolución, para identificar y seleccionar las relativas a la oferta de alojamiento turístico.

- No existía una base de datos informatizada de consulta de obras, pues la existente se correspondía a licencias posteriores a los años 90 y presentaba un nivel básico de detalle. Ello obligó al desglose de la información de las resoluciones de obras que se iban encontrando en papel, con la consiguiente labor archivística para encontrar los expedientes y proyectos de reforma de los alojamientos turísticos.

- La documentación del Área de Urbanismo y del Archivo municipal se encontraba en un inadecuado estado de conservación, mantenimiento y organización funcional.

- Existía un alto porcentaje de expedientes perdidos o extraviados.

- Los diversos y múltiples cambios normativos en la concepción de obra mayor y menor (alcance y naturaleza de las obras).

Durante el período de análisis (1955-2009), 930 de las 13.100 resoluciones de licencias urbanísticas otorgadas se correspondieron con establecimientos de alojamiento turístico (tabla 1). Su análisis siguió el siguiente proceso secuencial: 
Tabla 1

RESUMEN DE DATOS ESTADÍSTICOS EXTRAIIDOS DEL ANÁLISIS DE LICENCIAS URBANÍSTICAS DE REFORMA DE LA OFERTA DE ALOJAMIENTO TURÍSTICO EN PUERTO DE LA CRUZ

\begin{tabular}{llc}
\hline \multicolumn{2}{c}{ Información detallada } & Datos específicos \\
\hline \multicolumn{2}{l}{ Período de estudio } & $1955-2009$ \\
\hline Número de consultas de licencias de obras & 13.100 \\
\hline \multirow{3}{*}{ Número total de licencias otorgadas } & En establecimientos hoteleros & 600 \\
\cline { 2 - 3 } & En establecimientos extrahoteleros & 330 \\
\cline { 2 - 3 } & De oferta complementaria & 55 \\
\cline { 2 - 3 } & Total & 930 \\
\hline Número de consultas aproximadas de expedientes de obras & 600 \\
\hline
\end{tabular}

Fuente: Área de Urbanismo y Archivo municipal del Ayuntamiento de Puerto de la Cruz. Elaboración propia.

1) Revisión y tratamiento de las licencias urbanísticas, con el fin de corregir y, en su caso, añadir información a aquellas licencias que carecían de datos claves, imprecisiones y datos incomprensibles o dudosos.

2) Identificación de las licencias urbanísticas destinadas exclusivamente a la renovación de los alojamientos turísticos. Se descartaron aquéllas correspondientes a la construcción de hoteles o apartamentos turísticos, demoliciones de antiguos hoteles o de cambios de uso turístico a régimen extrahotelero o residencial se han excluido. Si bien cada licencia se corresponde con una reforma concreta, en algunos casos, ha comprendido varias, siendo, además de tipos diferentes.

3) Clasificación de las licencias según el tipo, identificando las de obra mayor, de obra menor y las de las actividades e instalaciones (tabla 2). Se ha intentado que esta clasificación englobe todos los contenidos en función de la naturaleza-contenido de la reforma y de su ubicación en los establecimientos alojativos (habitaciones, espacios comunes, espacios libres, etc.). Con ello se ha intentado tener una visión global y sistémica del conjunto de operaciones de renovación de los alojamientos turísticos.

4) Consulta de los expedientes y resoluciones de las licencias, con el fin de extraer datos específicos, como el presupuesto de ejecución material de las obras o el desglose pormenorizado de los tipos de reforma a realizar. Asimismo, esta información se completó con visitas a los establecimientos turísticos, así como la realización de entrevistas a personas relacionadas con los alojamientos (personal de recepción, directores y propietarios).

5) Clasificación de las licencias urbanísticas según la modalidad de alojamiento. Se ha procedido a la homogeneización y sistematización de la información referente a cada uno de los establecimientos de alojamiento turístico (antigüedad, categoría, número de plazas, etc.)

6) Integración de la información y datos estadísticos desagregados a través de un Sistema de Información Geográfica. 
Tabla 2

CLASIFICACIÓN DE LAS LICENCIAS DE OBRAS EN REFORMAS DE TIPO "LOGISTICO"

\begin{tabular}{|c|c|c|c|}
\hline \multirow{5}{*}{$\begin{array}{c}\text { Obras } \\
\text { mayores }\end{array}$} & \multirow{3}{*}{$\begin{array}{l}\text { Obras en los } \\
\text { edificios }\end{array}$} & $\begin{array}{c}\text { Reformas } \\
\text { estructurales }\end{array}$ & $\begin{array}{l}\text { - Intervenciones de adecuación, adaptación, consolidación o me- } \\
\text { jora estructural (pilares, forjados, vigas, cimientos, etc.) de los } \\
\text { establecimientos. } \\
\text { - Reaprovechamiento del espacio edificado para una posterior re- } \\
\text { forma interior y ampliación nuevos usos. } \\
\text { - Ampliaciones de los establecimientos (plantas, superficies li- } \\
\text { bres, etc.) o la consolidación de la estructura de los estableci- } \\
\text { mientos turísticos }\end{array}$ \\
\hline & & $\begin{array}{l}\text { "Construcciones } \\
\text { significativas", }\end{array}$ & $\begin{array}{l}\text { Actuaciones de mejoras y aporte de un valor añadido a los estable- } \\
\text { cimientos a través de equipamientos complementarios, tales como } \\
\text { salones multifuncionales para eventos y de tratamiento de belleza } \\
\text { o salud, la construcción de piscinas, Spa, garajes, zonas deportivas, } \\
\text { etc. }\end{array}$ \\
\hline & & $\begin{array}{l}\text { Intervenciones } \\
\text { dirigidas a la } \\
\text { seguridad y } \\
\text { adaptación de } \\
\text { la normativa en } \\
\text { materia turística }\end{array}$ & $\begin{array}{l}\text { Instalación de escaleras de emergencia y de incendios, construc- } \\
\text { ción de núcleos de comunicación internos a través de través de } \\
\text { pasos peatonales, etc.). }\end{array}$ \\
\hline & $\begin{array}{l}\text { Actividades } \\
\text { molestas }\end{array}$ & $\begin{array}{l}\text { Reformas de tipo } \\
\text { "logístico }\end{array}$ & $\begin{array}{l}\text { Construcción de depósitos de aguas residuales, instalaciones de } \\
\text { tanques subterráneos de gasoil, depósitos de agua, depuradoras de } \\
\text { aguas residuales, centros de transformación eléctrica, acondiciona- } \\
\text { miento de aire, etc. }\end{array}$ \\
\hline & $\begin{array}{l}\text { Obras } \\
\text { de demolición }\end{array}$ & \multicolumn{2}{|c|}{$\begin{array}{l}\text { Intervenciones en las que se procede a la demolición de diferentes elementos para la ade- } \\
\text { cuación, adaptación, consolidación o mejora en la distribución. }\end{array}$} \\
\hline \multirow{3}{*}{$\begin{array}{c}\text { Obras } \\
\text { menores }\end{array}$} & \multicolumn{2}{|c|}{$\begin{array}{l}\text { Obras relacionadas con la vía pública y } \\
\text { los exteriores de los establecimientos }\end{array}$} & $\begin{array}{l}\text { Colocación de rótulos, anuncios luminosos, anagramas, toldos en } \\
\text { las plantas baja de las edificaciones turísticas, tratamientos de fa- } \\
\text { chada, pintura, construcciones de rampas o accesos, colocación de } \\
\text { puertas de garaje, aperturas de huecos, o las demoliciones menores. }\end{array}$ \\
\hline & \multicolumn{2}{|c|}{$\begin{array}{l}\text { Obras menores de reparación y } \\
\text { construcciones menores }\end{array}$} & $\begin{array}{l}\text { Acondicionamientos de locales comerciales en los bajos de los es- } \\
\text { tablecimientos, reparación de cubiertas, sustitución de alicatados, } \\
\text { pavimentos, redistribución espacial en espacios concretos para } \\
\text { nuevos usos, acondicionamiento de zonas ajardinadas o de pisci- } \\
\text { na, reparación de balcones y terrazas, construcciones menores, etc. }\end{array}$ \\
\hline & \multicolumn{2}{|c|}{$\begin{array}{l}\text { Obras de remozamiento general de las } \\
\text { instalaciones }\end{array}$} & $\begin{array}{l}\text { Reformas interiores de alguna planta concreta, sótanos, entreplan- } \\
\text { ta, ampliaciones concretas de algún sector o acondicionamiento } \\
\text { general/parcial de espacios comunes, habitaciones o plantas con- } \\
\text { cretas. }\end{array}$ \\
\hline \multirow{2}{*}{$\begin{array}{l}\text { Actividades e } \\
\text { instalaciones- } \\
\text { aperturas- } \\
\text { cerramientos }\end{array}$} & \multicolumn{2}{|c|}{ De instalaciones y apertura de zanjas } & $\begin{array}{l}\text { Tratamientos de las aguas residuales con pozos absorbentes, aper- } \\
\text { turas de zanjas, instalaciones eléctricas o contraincendios }\end{array}$ \\
\hline & \multicolumn{2}{|c|}{ Cerramientos } & $\begin{array}{l}\text { Cerramientos o instalación de muros de protección, barreras mó- } \\
\text { viles o vallados de seguridad, así como las catas, movimientos de } \\
\text { tierra o excavaciones menores. }\end{array}$ \\
\hline
\end{tabular}

Fuente: elaboración propia. 


\section{IV.2. Resultados: el proceso de renovación de la oferta de alojamiento turístico de Puerto de la Cruz}

\section{IV.2.1. Análisis cuantitativo del número de licencias urbanísticas en materia de renovación}

Se han contabilizado 649 licencias de reforma de alojamientos turísticos durante el período de investigación, lo que supone una media de 12 licencias por año. Ello da cuenta del insuficiente proceso de renovación turística, sobre todo, si tenemos en cuenta que la media ha sido de 9 actuaciones por establecimiento alojativo (figura 1). No obstante, estos datos deben ser matizados, ya que, dependiendo del tipo de licencia otorgada y obra ejecutada, varias licencias pueden corresponderse a un mismo establecimiento de alojamiento.

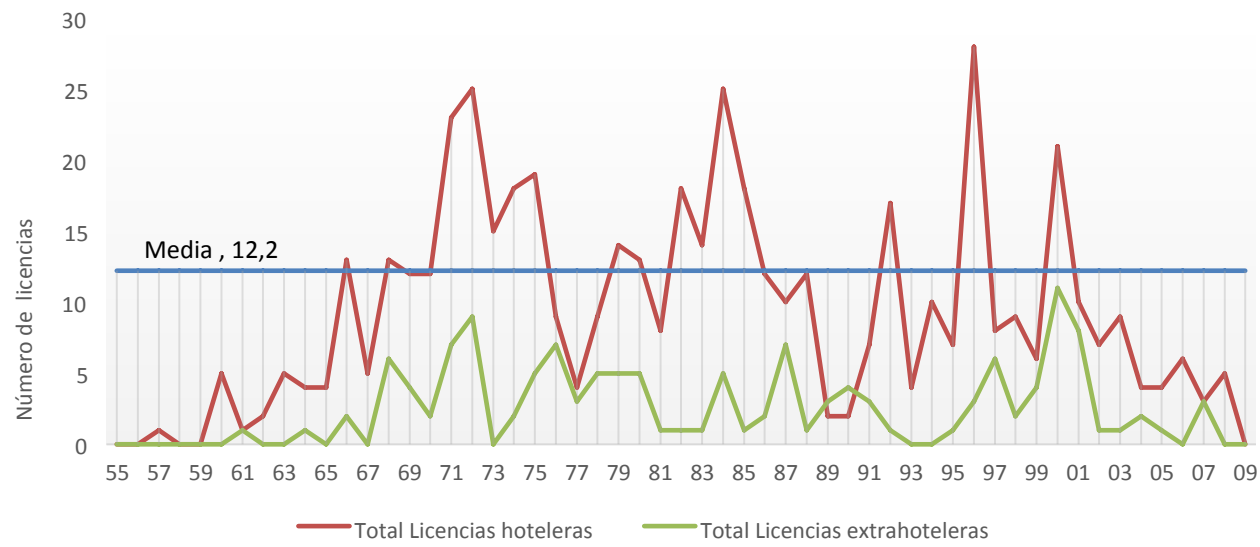

Fuente: Gerencia de Urbanismo y Archivo municipal del Ayuntamiento de Puerto de la Cruz. Elaboración propia.

Las reformas efectuadas con anterioridad a Ley 7/1995, de 6 de abril, de Ordenación del Turismo de Canarias, dan cuenta de una escasa actividad en esta materia. En este sentido, 23 establecimientos no han afrontado ningún tipo de reforma dirigida a un incremento de su calidad. Además, sólo se han contabilizado 15 establecimientos de alojamiento turístico que han acometido reformas integrales (figura 2). Asimismo, éstas se han limitado al proceso de "tres pes" (pintar, pavimentar y parchear), con pequeñas obras de sustitución, acondicionamiento y decoración de los edificios turísticos y, por tanto, de ornato y mantenimiento.

Por su parte, casi el 50\% de las intervenciones acometidas con posterioridad a la Ley $7 / 1995$, que, en cierta medida, marca el punto de partida dentro del marco legislativo canario en materia de renovación turística en Canarias, se corresponden con la estricta obra menor. De esta manera, se han dirigido sobremanera al mero mantenimiento o el cumplimiento de la normativa turística. 

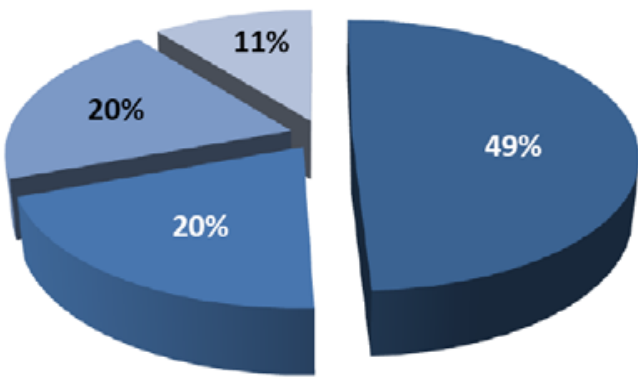

- Obra menor o de estricta conservación/mantenimiento posterior a 1995

Actuaciones de modo integral posterior a 1995

No se tiene constancia de reformas

Reformas con anterioridad a 1995

Fuente: elaboración propia a partir de las Licencias urbanísticas de Ayuntamiento de Puerto de la Cruz.

A partir del año 2003 se produjo un estancamiento prácticamente total del proceso de renovación de la oferta de alojamiento turístico de Puerto de la Cruz (figura 3). Además de la pérdida de competitividad de esta área turística, a favor de las que se estaban consolidando en el Sur de la Isla, la promulgación del Decreto 10/2001, de 22 de enero, por el que se regulan los estándares turísticos, constituye el factor que explica esta ausencia de solicitudes de licencias urbanísticas. Ello se debe que todos los parámetros físicos son de obligado cumplimiento para la obtención de la preceptiva autorización previa administrativa prevista en el artículo 24 de la Ley 7/1995. A su vez, este Decreto constituye un mandato legal al planificador, que reduce el ámbito de su discrecionalidad para la integración y observación obligatoria por el planeamiento urbanístico (García de Enterría y Parejo, 1979). Se reveló como preceptivo para habilitar la concesión de la correspondiente licencia municipal de renovación de los alojamientos turísticos. Supone un condicionante para la ampliación y renovación de los establecimientos turísticos de alojamiento, debido a su compleja aplicación en determinados establecimientos, en cuanto sus características no les permiten cumplir tales estándares urbanísticos. Por último, prohíbe su otorgamiento hasta que se acredite la terminación de las obras de urbanización de la etapa que corresponda, con lo cual se establece un cierto condicionante a escala supramunicipal al crecimiento descontrolado de la oferta de alojamiento turístico, a la vez que positiva la obligación de que las autorizaciones previas verifiquen la compatibilidad del proyecto con el correspondiente Plan Insular de Ordenación.

Esta circunstancia ha cambiado con la aprobación del Plan de Modernización, Mejora e Incremento de la Competitividad de Puerto de la Cruz (Decreto 107/2015, de 22 de mayo). Se trata de instrumentos de ordenación territorial y gestión urbanística creados en la Ley 6/2009, siendo completados y consolidados en la Ley 2/2013. Estos han servido de soporte instrumental y cobertura para viabilizar y agilizar los convenios urbanísticos, cuya firma previa se plantea como un requisito indispensable, sobre todo, en los procesos de regeneración de los establecimientos de alojamiento turístico. Además, su carácter excepcional, vigencia indefinida y escala precisa, permite viabilizar y agilizar la ejecución de los proyectos de renovación y, sobre todo, la aplicación de los incentivos contemplados en ambas normas. 
Figura 3

EVOLUCIÓN DEL NÚMERO DE LICENCIAS POR MODALIDAD ALOJATIVA EN PUERTO DE LA CRUZ Y SU RELACIÓN CON ALGUNOS FACTORES CONDICIONANTES (1999-2009)

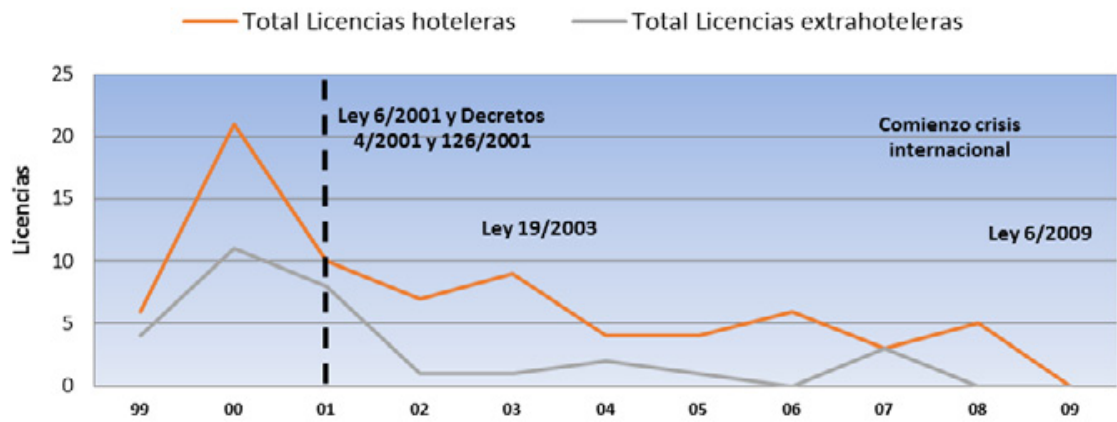

Fuente: elaboración propia a partir de las Licencias urbanísticas de Ayuntamiento de Puerto de la Cruz.

\section{IV.2.2. La aplicación real de la renovación hotelera a través de las licencias urbanísticas}

Las reformas de los establecimientos hoteleros y extrahoteleros se corresponden mayoritariamente a obras menores, de mantenimiento y conservación, representando el $80 \%$ del total de reformas (figura 4).

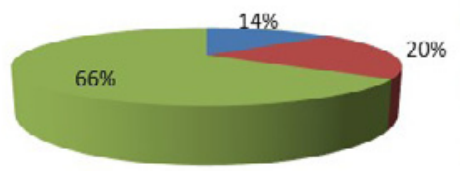

Modalidad hotelera

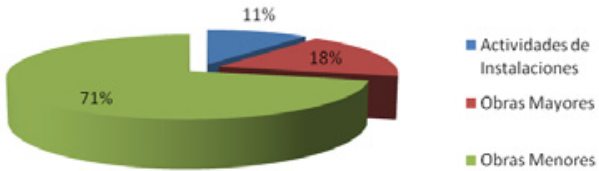

Modalidad extrahotelera

Fuente: elaboración propia a partir de las Licencias urbanísticas de Ayuntamiento de Puerto de la Cruz.

En el caso hotelero, prácticamente la mayoría (el 60\%) de las operaciones ejecutadas son de obra mayor, seguidas de las denominadas "actividades molestas" (el 40\%) que incluyen aquellas reformas dirigidas a la mejora de la funcionalidad de los hoteles (servicios básicos, etc.). Las obras de demolición representan únicamente un 1,9\% del total de las obras mayores; ello resulta lógico teniendo en cuenta las dificultades para la implementación de este tipo de estrategia en el destino derivado de la fuerte concentración parcelaria y elevada atomización existente en gran parte del destino.

Desde el punto de vista del tipo de reforma mayoritaria (figura 5), las reformas estructurales han sido prácticamente inexistentes, reduciéndose a catorce. Por el contrario, las obras mayores acometidas se han dirigido fundamentalmente al cumplimiento con la normativa en materia de seguridad (el 33\%), siendo el porcentaje más elevado del total de reformas. 

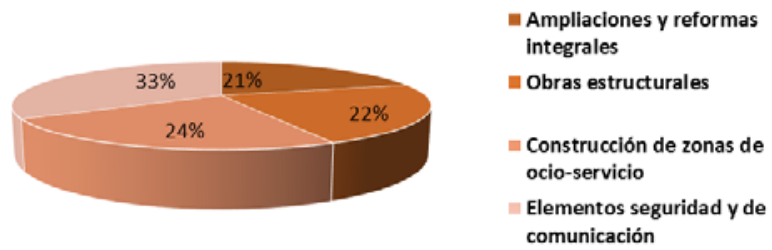

Fuente: Gerencia de Urbanismo y Archivo municipal del Ayuntamiento de Puerto de la Cruz. Elaboración propia.

Por tanto, aunque existen algunas actuaciones significativas en algunos hoteles que han venido manteniendo una actividad relevante en materia de renovación, esta área turística se caracteriza por la ausencia de las citadas "rehabilitaciones integrales" de la Ley 6/2009 o "totales" de la 2/2013. Ello explica el déficit de operaciones correspondientes al apartado funcional de las instalaciones como fórmula de un cambio tendencial del modelo de negocio hotelero, tanto las dirigidas a la construcción de alguna infraestructura deportiva o de ocio, como a la diversificación o mejora de sus productos o servicios turísticos, con la instalación de salas de discotecas, sauna, salones multifuncionales, piscinas, zonas de tratamiento, Spa, gimnasio, ampliación de jardines, etc. La falta de este tipo de actuaciones ha llevado a que gran parte de los establecimientos hoteleros tengan unas características más o menos homogéneas en cuanto a recursos.

Las licencias de obras menores fueron 331. Por lo general, las operaciones de mantenimiento están presentes en prácticamente la totalidad de los establecimientos hoteleros. Evidentemente, el número, la calidad y el nivel de profundidad de las reformas han sido desiguales, como consecuencia de las características y niveles de exigencia de cada uno de los establecimientos ante la planificación de los procesos de renovación vía mantenimiento de las edificaciones a medio y largo plazo, así como el interés y capacidad del empresario de reinvertir en las mismas.

Considerando la heterogeneidad de reformas acometidas en las distintas zonas de los hoteles, las reformas de obra menor se han caracterizado por los siguientes rasgos:

a) Reformas en las fachadas y espacios libres. Este tipo acumula el mayor número de licencias, casi el 50\%. Ello pone de manifiesto el interés del propietario/promotor de intervenir en elementos edificatorios relacionados con la imagen y el ornato del edificio. A su vez, que se solicitan, sobre todo, cuando se trata de actuaciones "visibles" y que son susceptibles de sanción cuando no se hace.

Las operaciones más comunes han estado dirigidas hacia el tratamiento de las fachadas, correspondiéndose con un 36\% del total de intervenciones. El $80 \%$ ha consistido en la instalación de letreros (especialmente, luminosos), rótulos, toldos o anagramas. Otro tipo de licencias concedidas se corresponden con actuaciones dirigidas a la sustitución de los elementos de mayor desgaste, a modo de mero mantenimiento, que ha ralentizado, en muchos casos, el deterioro del ornato de los elementos físicos y funcionales de los propios establecimientos.

Las obras realizadas en las zonas de ajardinamiento representan sólo el $15 \%$ del total de las reformas. Estas actuaciones han incidido en una mejora circunstancial 
de estas zonas, tanto a través de su acondicionamiento y embellecimiento como de la reparación de los jardines, solárium, bar-terrazas y piscinas.

b) Reformas en las zonas nobles o comunes de los establecimientos hoteleros. Aglutinan casi el $25 \%$ del total de intervenciones. Estas obras han consistido fundamentalmente en la sustitución y renovación de los alicatados, así como el pavimentado de estas zonas. También se han centrado en los elementos de uso intensivo, por el elevado tránsito de los clientes. Asimismo, han consistido en actuaciones de diseño y decoración, especialmente a través de la pintura. Lo mismo sucede con la redistribución de los espacios existentes en las zonas de recepción, office o algunos salones, con el fin de lograr un mayor aprovechamiento o dotándolos de una nueva funcionalidad. Las obras en los cuartos de baño representan casi el $60 \%$ del total de intervenciones, consistiendo, sobre todo, en la sustitución de las piezas sanitarias y los revestimientos.

c) Reformas en las habitaciones. Éstas se han orientado fundamentalmente a la sustitución parcial de acabados, así como a labores de pintura. De este modo, podemos entender que los procesos de modernización de las habitaciones han estado focalizadas al cumplimiento de los ciclos de mantenimiento y reposición de los elementos de mayor desgaste, en detrimento de la búsqueda de nuevas formas de atracción del cliente, mediante la adaptación a las nuevas tendencias en materia de mobiliario, decoración, diseño, amplitud o confort. Así, casi el 50\% de las reformas se han materializado en el interior de los cuartos de baño, acometiendo reposiciones o reparaciones de los sanitarios e instalaciones, así como cambios en alicatados y pavimentos, al tener una vida más corta, frente a otro tipo de intervenciones de mayor profundidad.

Por el contrario, las actuaciones de tematización o especialización, de personalización o de adecuación de las habitaciones a las tendencias actuales del diseño y mobiliario, así como la modernización de las infraestructuras básicas (bañeras de hidromasaje, camas King, Tv panorámicos, etc.) han sido muy limitadas.

d) Reformas menores de índole general. Han consistido fundamentalmente en intervenciones de redistribución, con el fin de mejorar y "reaprovechar" el espacio existente. Estas se han desarrollado en zonas de office y de servicio, con la ampliación de salones, pequeñas dependencias y otros servicios, en su mayoría, dedicados al área de economato. Lo mismo ha sucedido con el tratamiento y distribución espacial de las plantas superiores de los establecimientos (áticos y sobreáticos), que, en algunos hoteles, ha servido para la creación de nuevas habitaciones de calidad superior y, por tanto, de una mayor rentabilidad (suites, junior suites, doble superior, etc.).

Estos resultados han permitido corroborar el déficit de renovación del área turística Puerto de la Cruz. Éstas se han basado fundamentalmente en obras menores, de conservación y mantenimiento físico de los establecimientos de alojamiento turístico.

\section{CONCLUSIONES FINALES}

En este trabajo de investigación se ha planteado la oportunidad que supone la licencia urbanística como un indicador viable para evaluar los procesos de renovación de la oferta de alojamiento turístico. El análisis del número y tipología permite contrarrestar el déficit 
de información pública existente acerca de los procesos de renovación de la oferta de alojamiento a escala nacional y regional, así como la heterogeneidad de los sistemas de información disponibles en esta materia.

Desde este punto de vista, se ha hecho especial hincapié en la importancia de la licencia urbanística como una herramienta válida que proporciona un considerable número de variables medibles para la mejora de la evaluación de los procesos de renovación de los alojamientos turísticos. No obstante, se reconoce que no se trata de una unidad homogénea de análisis, en cuanto está condicionada a ciertas limitaciones (fuentes homogéneas, normativa y cuestiones legales, diversidad de licencias, naturaleza y alcance de las mismas, localización, etc.) que restan capacidad analítica al proceso metodológico y a los propios resultados que se puedan obtener.

A pesar de ello, su aplicación al análisis al proceso de renovación física de los establecimientos de alojamiento turístico de un área turística de Canarias, ha permitido contrastar su potencialidad en relación con alguna de las siguientes cuestiones:

a) Aporta suficientes variables de análisis para lograr el conocimiento exhaustivo sobre el proceso de renovación de la oferta de alojamiento en consonancia con su propia evolución.

b) Permite ser objeto de una sistematización conceptual como alternativa al problema de la heterogeneidad de fuentes de información disponibles. La clasificación de las licencias urbanísticas de renovación nos ha permitido analizar el grado de renovación de los alojamientos turísticos en función de la tipología de licencia. Esta ha posibilitado desgranar y ahondar de forma más veraz la información recibida por parte de las operaciones de renovación.

En síntesis, los resultados demuestran la utilidad de la licencia urbanística en los procesos de renovación del sector hotelero. Aún con estos datos, se hace necesario incidir en nuevos estudios y casos en otras áreas turísticas con el fin de homogeneizar, avanzar y mejorar la metodología propuesta para seguir corroborando su utilidad. De esta forma, consideramos preciso mejorar el proceso analítico en materia estadística de la renovación de la oferta de alojamiento turístico para la planificación y gestión de destinos consolidados y con ello permitir un mayor conocimiento.

\section{BIBLIOGRAFÍA}

ABDELGHANY, M., y ABOTALEBB, A. (2014). Causes of hotel renovation delays in Egypt. Creative Construction Conference 2014.

AGARWAL, S. (2002): "Restructuring seaside tourism. The resort lifecyle", Annals of Tourism Research, vol. 29 (1), pp. 25-55.

ÁlVAREZ ALONSO, A. (2004): "El ciclo de vida de los destinos turísticos litorales", en Álvarez Alonso, A.; Hernández Hernández, J. y Simancas Cruz, M. R. (dirección y coordinación). Turismo y territorio en la sociedad globalizada. Ayuntamiento de la Villa de Adeje / Instituto Pascual Madoz del Territorio, Urbanismo y Medio Ambiente. Universidad Carlos III. Santa Cruz de Tenerife, pp. 124-155.

ANTON, S. (2004): "De los procesos de diversificación y cualificación a los productos turísticos emergentes. Cambios y oportunidades en la dinámica reciente del turismo litoral", Papeles de Economía Española, n 102, pp. 316-332. 
ANTON CLAVÉ, S. (2011): "Dinámicas de reestructuración de los destinos turísticos litorales del Mediterráneo. Perspectivas y condicionantes", en López, D. (Ed.): Renovación de destinos turísticos consolidados. Valencia, Tirant Lo Blanch, pp. 23-40.

ARTIGUES ANTONI A. y BLÁZQUEZ SALOM, B. (2012): ¿Reconversión o desregulación? Análisis de planes de reconversión turísticoinmobiliaria de la Playa de Palma (Mallorca)", Cuadernos de Turismo, $\mathrm{n}^{\circ}$ 29, pp. 11-34

BULLEJOS CALVO, C. y ORTEGA MARTÍN, E. (2008): “Licencias Urbanísticas”, en Enciclopedia de la Administración Local. Editorial La Ley.

CASTELAO RODRÍGUEZ, J. (2008): Licencias urbanísticas, en San Cristóbal Reales, S. (coord.): Manual de Derecho de la Construcción págs. 1019-1070

CHINCHILLA PEINADO, J.A. (2009): "La rehabilitación de los establecimientos turísticos alojativos como manifestación del desarrollo urbanístico sostenible. El ejemplo de Canarias", Práctica Urbanística, nº 87, pp. 64-77.

CLEGG, A. y ESSEX, S. (2000): "Restructuring in Tourism: The Accommodation Sector in a Major British Coastal Resort". International Journal of Tourism Research, 2, pp. 77-95.

CORGEL, J.B., DEROOS, J.A. y FITZPATRICK, K. (2011): Developing and renovating hospitality properties [Electronic version]. Cornell University

DE LA CONCHA BERGILLOS, C. (2010): "Las licencias urbanísticas”, en Hernández Gonzñalez, F. y Villar Rojas, F. (Coord.): Derecho urbanístico de Canarias, pp. 441-482.

DOMPER FERRANDO, J. (2009): "Licencias urbanísticas”, en Martín Rebollo, L. y Bustillo Bolado, R. (Coord.): Fundamentos de Derecho Urbanístico, vol. 2, pp. 1.067-1.098.

DONAIRE, J.A., y MUNDET I CERDÁN, Ll. (2001): “Estrategias de reconversión turística de los municipios litorales catalanes", Papers de Turisme, n 29, pp. 50 -66.

DORTA RODRIGUEZ, A. (2011): "Crisis económica y cierre de establecimientos alojativos en destinos turísticos consolidados. El caso de Puerto de La Cruz (Tenerife)", en Espacios y destinos turísticos en tiempos de globalización y crisis. Vol. II, Madrid. AGE, pp. 183-197.

DORTA RODRÍGUEZ, A. (2013): “Algunos apuntes sobre la renovación hotelera como estrategia de reestructuración de destinos turísticos consolidados", Revista Turismo (Escuela Universitaria de Turismo Iriarte), Vol. 3-4, pp. 33-37

DORTA RODRÍGUEZ, A. (2015): Análisis del proceso de renovación de la oferta turística de alojamiento en destinos consolidados: el caso de Puerto de la Cruz (Tenerife). (Tesis doctoral). Servicio de publicaciones. Universidad de La Laguna. San Cristóbal de La Laguna.

DORTA RODRÍGUEZ, A. (2016): "El proceso de renovación de la oferta de alojamiento turístico en destinos consolidados: el caso de Puerto de la Cruz (1955-2009)", Cuadernos de Turismo, no 38, pp. 115-145.

DORTA RODRÍGUEZ, A. y GARCÍA CRUZ, J.I. (2010): “Turismo en tiempos de crisis. La renovación urbana como estrategia en destinos turísticos maduros, el caso de Puerto de la Cruz (Tenerife)", en XIX Coloquio de Historia Canario Americana.

DORTA RODRÍGUEZ, A., SIMANCAS CRUZ, M.R. y GARCÍA CRUZ, J.I. (2011): “La renovación del Hotel Beatriz Atlantis \& Spa (Puerto de la Cruz, Islas Canarias). Un ejemplo de recualificación de la oferta de alojamiento obsoleta en destinos turísticos consolidados", en Seminario Internacional sobre renovación y reestructuración de destinos turísticos consolidados del litoral. Alicante. 
FERNÁNDEZ RODRÍGUEZ, T. R. (2008): Manual de Derecho Urbanístico. La Ley-El Consultor, Madrid.

GARCÍA CRUZ, J.I. (2010): “Renovación vs creación de espacios turísticos. Efectos territoriales de las Directrices de Ordenación del Turismo de Canarias", en XV Congreso de la Asociación Española de Expertos en Turismo. AECIT / Facultad de Ciencias Económicas y Empresariales. Universidad de La Laguna.

GARCÍA CRUZ, J.I. (2015): El impacto territorial del tercer boom turístico de Canarias. Servicio de Publicaciones de la Universidad de La Laguna. Series Tesis doctoral.

GARCÍA DE ENTERRÍA, E. y PAREJO ALFONSO, L. (1979): Lecciones de Derecho Urbanístico, Ed. Cívitas.

GONZÁLEZ HERNÁNDEZ, M., LEÓN GONZÁLEZ, C.J., y PADRÓN FUMERO, N. (2006): "Obsolescencia y políticas de renovación medioambiental en el sector turístico", Cuadernos Económicos de ICE, $\mathrm{n}^{\circ}$ 71, pp. 153-176.

GONZÁLEZ LEMUS, N., HERNÁNDEZ PÉREZ, M., y SÁNCHEZ GARCÍA, I. (2005): El Puerto de la Cruz. De ciudad portuaria a turística. Centro de Iniciativas Turísticas de Puerto de la Cruz, Puerto de la Cruz (Tenerife).

GONZÁLEZ REVERTÉ, F. (2012): "El modelo de reestructuración turística de la Costa Daurada”, en Renovación y reestructuración de destinos turísticos en áreas costeras: marco de análisis, procesos, instrumentos y realidades / coord. por José Fernando Vera Rebollo, Isabel Rodríguez Sánchez, 2012, ISBN 978-84-370-8863-1, págs. 219-241.

IVARS, J., RODRÍGUEZ, I. y VERA, J. F. (2012): “La reinvención de los destinos turísticos maduros: modelos evolutivos y dinámicas turístico-territoriales. Benidorm como paradigma”. En Vera, J.F. y Rodríguez, I. (Eds.): Renovación y reestructuración de destinos turísticos en áreas Costeras. Marco de análisis, procesos, instrumentos y realidades. Valencia, Universidad de Valencia, 269-296.

KNOWLES y CURTIS (1999): "The market viability of European mass tourist destinations. A Post-Stagnation Life-Cycle Analysis”. International Journal of Tourism Research, vol. 1 (4), pp. 87-96.

LEDESMA GONZÁLEZ, O. (2012): El modelo turístico de Puerto de la Cruz. Presente y futuro. Nivaria Ediciones, San Cristóbal de La Laguna. [ISBN: 978-84-933941-6-5]

LLORCA AFONSO, E. y SOSA DÍAZ-SAAVEDRA, A. (2010): "Procesos de reciclaje aplicados al turismo de masas en el Sur de Gran Canaria”, en VV.AA: Congreso Internacional Sustainable Building 2010.

LÓPEZ OLIVARES D. y FERRERES BONFILL, J.B. (2011): "La reestructuración de los destinos consolidados del litoral castellonense. el caso de Benicàssim (Castellón, Comunitat Valenciana)", en Actas del Seminario Internacional sobre renovación y reestructuración de destinos turísticos consolidados del litoral. Alicante del 24-25 de noviembre. ISBN. 978-84-695-0791-9.

MARTIN AZAMI, D. (2005): Determinantes estratégicos de la fidelidad del turista en destinos maduros. (Tesis de Doctorado. Universidad de La Laguna).

MARTIN MARTIN, V.O. (1998): "El Valle de la Orotava. Un destino turístico con una larga tradición histórica”, en La actividad turística española en 1996 (Edición 1997). AECIT, Nexo Ediciones. Madrid.

MIRALLAVE IZQUIERDO, V. (2004): “Consideraciones sobre la renovación del espacio turístico canario", Cartas Urbanas, n 9, pp. 84-93. 
OBIOL, E. y FERRANDIS, A. (2011): “Gandía y sus prácticas de renovación turística”. Seminario Internacional Renovación y Reestructuración de Destinos Turísticos Consolidados del Litoral. Universidad de Alicante, Instituto Universitario de Investigaciones Turísticas.

ORTEGA BERNARDO, J. (1997): "Las licencias urbanísticas”, Revista de Derecho Urbanístico y Medio Ambiente, ${ }^{\circ}$ 154, pp. 69-120.

POTTER, R.B. y PHILLIPS, J. (2004): "The rejuvenation of tourism in Barbados 1993-2003 reflections on the Butler model". Geography, vol. 89, pp. 240-247.

SANTOS PAVÓN. E. y FERNÁNDEZ TABALES, A. (2010): "El litoral turístico español en la encrucijada: entre la renovación y el continuismo", Cuadernos de Turismo, n 25 , pp. 185-206.

SIMANCAS CRUZ, M.R. (2010): "La renovación edificatoria de la oferta turística de alojamiento en destinos consolidados. La experiencia de Canarias", Cuadernos de Geografía, no 87, pp. 23-44.

SIMANCAS CRUZ, M.R. (2011): "El fracaso de la renovación de áreas turísticas consolidadas de litoral a través de la sustitución de la oferta de alojamiento obsoleta. La experiencia de las Islas Canarias", Cuadernos de Turismo, n² 27, pp. 869-899.

SIMANCAS CRUZ, M.R. (2012): "Evaluando políticas públicas de renovación de destinos turísticos maduros: el proceso de reconversión turística de Canarias", en Vera Rebollo, J.F. y Rodríguez, I. (Coords.) Renovación y reestructuración de destinos turísticos en áreas costeras: marco de análisis, procesos, instrumentos y realidades, pp. 163-199;

SIMANCAS CRUZ, M.R. (2015): La moratoria turística de Canarias. La reconversión de un destino maduro desde la Ordenación del Territorio. San Cristóbal de La Laguna, Servicio de Publicaciones de la Universidad de La Laguna.

SIMANCAS CRUZ, M.R. y GARCÍA CRUZ, J.I. (2013): "La dimensión territorial de la residencialidad en las áreas turísticas consolidadas de Canarias", Boletín de la Asociación de Geógrafos Españoles, no 63, pp. 271-299.

SIMANCAS CRUZ, M.R. y HERNÁNDEZ MARTÍN, R. (Coords.) (2015): Reinventando alojamientos turísticos. Casos de éxito y soluciones innovadoras. Cátedra de Turismo CajaCanarias-Ashotel-Universidad de La Laguna.

VERA REBOLLO, J.F., y BAÑOS, C.J. (2010): "Renovación y reestructuración de los destinos turísticos consolidados del litoral. Las prácticas recreativas en la evolución del espacio turístico", Boletín de la Asociación de Geógrafos Españoles, nº 53 pp. 329-353.

VERA REBOLLO, J.F., RODRÍGUEZ, I. y CAPDEPÓN, M. (2010): “Reestructuración y competitividad en destinos maduros de sol y playa: la renovación de la planta hotelera de Benidorm", en XIII Congreso Internacional de Turismo, Universidad y Empresa. Universitat Jaume I, Castellón.

VILLAR ROJAS, F. (2015): "Crónica sobre la construcción de un marco legal para la renovación del espacio turístico en Canarias”, El Consultor Urbanístico.

VILLAR ROJAS, F. (2016): “Crónica sobre la construcción de un marco legal para la renovación del espacio turístico en Canarias", Práctica Urbanística, nº 138, Sección Estudios, enero 2016.

WILLIAMS, A.M. y MONTANARI, A. (1995): "Introduction: tourism and economic restructuring in Europe", en Montanari, A. y Williams, A.M. (Eds.): European tourism. Regions, spaces and restructuring. John Wiley \& Sons, West Sussex, pp. 1-15.

YEPES, V. (1996): "Calidad de diseño y efectividad de un sistema hotelero". Papers de Turisme, n 20, pp. 137-167. 